\title{
Successful Treatment of Hypersensitivity Pneumonitis Caused by Grifola frondosa (Maitake) Mushroom Using a HFA-BDP Extra-fine Aerosol
}

\author{
Hiroshi TANaKa, Kazunori Tsunematsu*, Naohito NAKAmura*, Kazuhiko SuZUKI, \\ Nobuyuki TANAKA, Isao TAKEYA*, Toyohiro SAIKAI and Shosaku ABE
}

\begin{abstract}
We successfully treated a patient with occupational hypersensitivity pneumonitis (HP) caused by Grifola frondosa (Maitake) mushroom spore with an extra-fine aerosol corticosteroid; beclomethasone dipropionate (BDP) dissolved in hydrofluoroalkane-134a (HFA). A 49year-old woman developed respiratory symptoms 3 months after beginning work on a mushroom farm. She was diagnosed as HP based on radiological and serological findings. Oral prednisolone therapy improved her HP and she returned to the same farm. Her HP relapsed after 5 months, and daily $400 \mu \mathrm{g}$ of HFA-BDP was administered with gradual improvement. An extra-fine particle inhaled corticosteroid might reach appropriate alveoli to be effective therapy for mild HP.

(Internal Medicine 43: 737-740, 2004)
\end{abstract}

Key words: hypersensitivity pneumonitis, mushroom spore, inhaled corticosteroid, hydrofluoroalkane, beclomethasone dipropinate

\section{Introduction}

There are several recent reports of hypersensitivity pneumonitis (HP) induced by inhaled mushroom spores (15), and mushroom farms carry a significant risk for HP. The principle treatment for HP is avoidance of causative antigens and systemic steroids. In children with HP, oral prednisolone followed by nebulized budesonide is effective for $\operatorname{HP}(6,7)$, however there are no reports of a single drug therapy using an inhaled corticosteroid for HP. Hydrofluoroalkane-134a
(HFA)-beclomethasone dipropionate (BDP) $\left(\mathrm{QVAR}^{\circledR}\right)$ was formulated in a metered-dose inhaler (MDI) to deliver small particles of mean size of $1.1 \mu \mathrm{m}$, which can easily reach peripheral airways and alveolar spaces. In this report, we describe the first case of HP caused by Grifola frondosa (Maitake) mushroom (Fig. 1) spore, and the usefulness of single treatment with HFA-BDP.

\section{Case Report}

A 49-year-old woman smoker, who had developed a productive cough and recurrent fever, was admitted to the hospital in December 2002. She had worked for 3 months in an indoor mushroom farm, where edible Maitake mushroom had been cultivated since June 2002. She first noticed cough and low grade recurrent fever one month after beginning work. She had worn a N-95 mask during work, but she sometimes removed the mask because of the sensation of dyspnea. Her respiratory symptoms worsened in the farm with fever appearing after several hours, and improved during holidays. She visited the clinic and was diagnosed as cough variant asthma and treated with $600 \mu \mathrm{g} /$ day of CFCBDP using a MDI, but fever with a productive cough persisted, and she was referred to our hospital. Her percutaneous oxygen saturation was $97 \%$. Physical examination and routine laboratory studies were normal except for a raised serum surfactant protein D of $157.2 \mathrm{ng} / \mathrm{ml}$ (cut off level, $110 \mathrm{ng} / \mathrm{ml}$ ) and serum KL-6 $644 \mathrm{U} / \mathrm{ml}$ (cut off level, $500 \mathrm{U} / \mathrm{ml}$ ). A chest roentgenogram showed diffuse reticulo-nodular shadowing and chest CT scans demonstrated ground-glass opacities and faint centrilobular nodules (Fig. 2). She was hypoxemic with a $\mathrm{PaO}_{2}$ of 70.5 Torr during nasal oxygen supply $(3 \mathrm{l} / \mathrm{min})$. Pulmonary function tests revealed a VC of $3.09 l(119.2 \%$ of predicted); an $\mathrm{FEV}_{1}$ of $2.68 l$ (120.7\% of predicted); an

From the Third Department of Internal Medicine, Sapporo Medical University School of Medicine, Sapporo, *Tomakomai Prefecture Hospital, Tomakomai and **Esashi Prefecture Hospital, Esashi

Received for publication January 28, 2004; Accepted for publication April 20, 2004

Reprint requests should be addressed to Dr. Hiroshi Tanaka, the Third Department of Internal Medicine, Sapporo Medical University School of Medicine, South-1, West-16, Chuo-ku, Sapporo 060-8543 


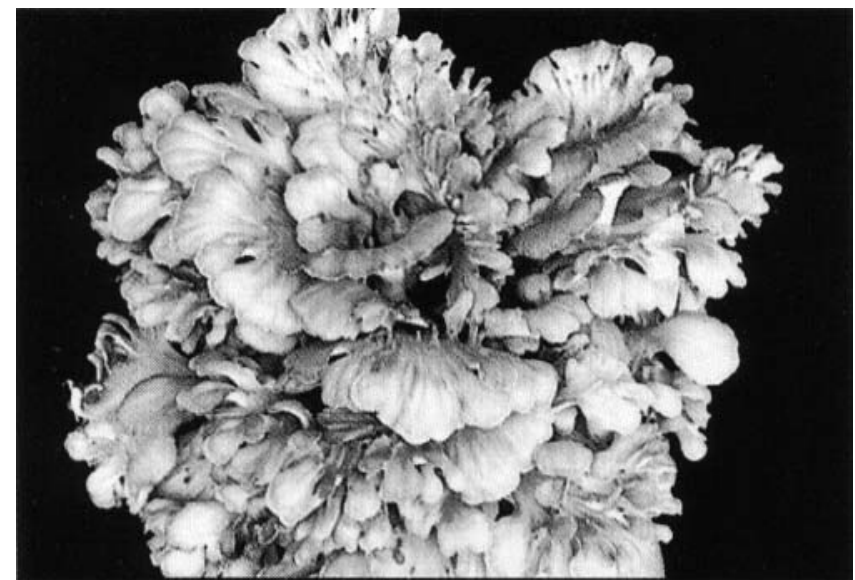

Figure 1. Grifola frondosa (Maitake) mushroom.

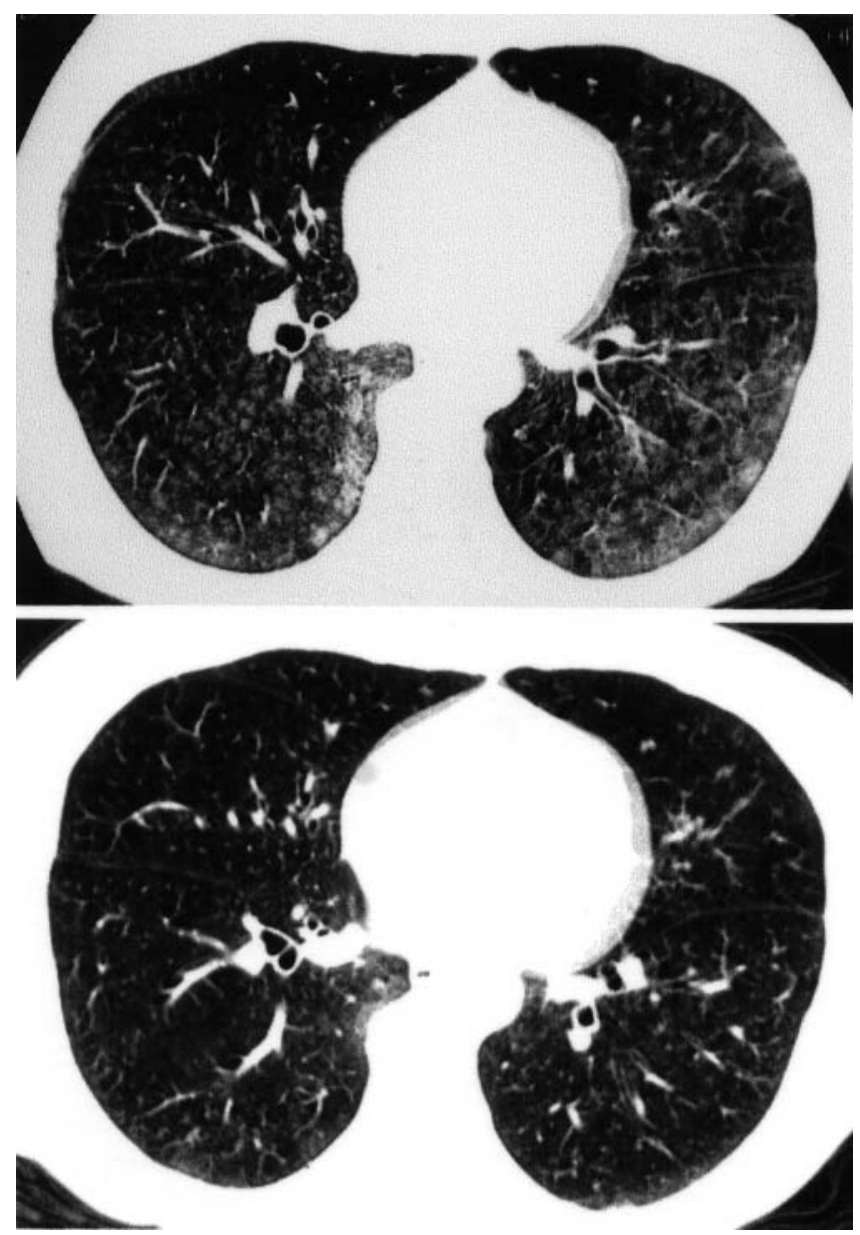

Figure 2. Chest CT scans with $1 \mathrm{~mm}$ collimation before treatment on December 11, 2002 (top) and after therapy with fine particle inhaled corticosteroid on November 25, 2003 (bottom). Ground-glass opacities and centri-lobular nodules were markedly reduced after the treatment.

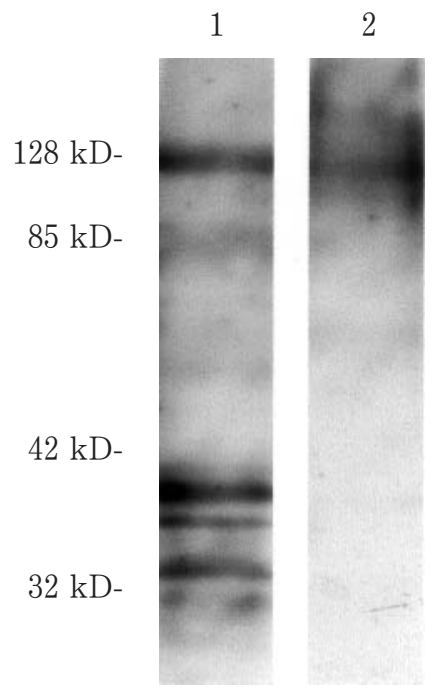

Lane 1: Patient

Lane 2: Healthy control

Figure 3. Western blot analysis of the patient's and the control's serum to Grifola frondosa (Maitake) spore antigen, showing positive bands at $33 \mathrm{kD}, 35 \mathrm{kD}$, and $38 \mathrm{kD}$.

$\mathrm{FEV}_{1} / \mathrm{FVC}$ ratio of $86.2 \%$; and decreased diffusion capacity of the lung for carbon monoxide (DLco; $48.7 \%$ of predicted). Bronchoalveolar lavage fluid (BALF) produced a total cell yield of $8.0 \times 10^{5} / \mathrm{ml}$ and the differential count showed $7.2 \%$ pulmonary alveolar macrophages; $48.9 \%$ lymphocytes; $40.5 \%$ neutrophils; $2.3 \%$ eosinophils; and the CD4/CD8 ratio of lymphocyte surface marker was 0.5 . Western blot analysis using Maitake mushroom spore antigens and her serum shows positive bands at $33 \mathrm{kD}, 35 \mathrm{kD}$, and $38 \mathrm{kD}$ (Fig. 3). Serum precipitins to Saccaropolyspora Rectivirgula, Thermoactinomyces vulgaris, and Aspergillus fumigatus were all negative. Tests for serum specific IgE for $12 \mathrm{com}$ mon antigens were negative. By avoiding Maikate mushroom spore antigens she improved, but relapsed in one month. Then $20 \mathrm{mg}$ of prednisolone was administered and she improved quickly by February 28, 2003 (Fig. 4). She returned to the same farm and changed her work place from the harvesting and packing room to the delivery section, where the level of airborne Maitake mushroom spores was very low. She used a N-95 mask, and avoided exposure to mushroom spores, consequently she had minimal respiratory symptoms for about 5 months. On August 6, she developed a productive cough and fever, and her chest roentgenogram again showed reticulo-nodular shadowing. She was hypoxemic with a $\mathrm{PaO}_{2}$ of 69.2 Torr in room air, serum creacting protein was elevated slightly to $0.6 \mathrm{mg} / \mathrm{dl}$, therefore we diagnosed her as having recurrent HP. She refused hospital admission; therefore we administered inhaled HFA-BDP (400 $\mu \mathrm{g} /$ day, twice a day). Her respiratory symptoms gradually decreased. On November 25, although she still had a 
HP by Maitake Mushroom

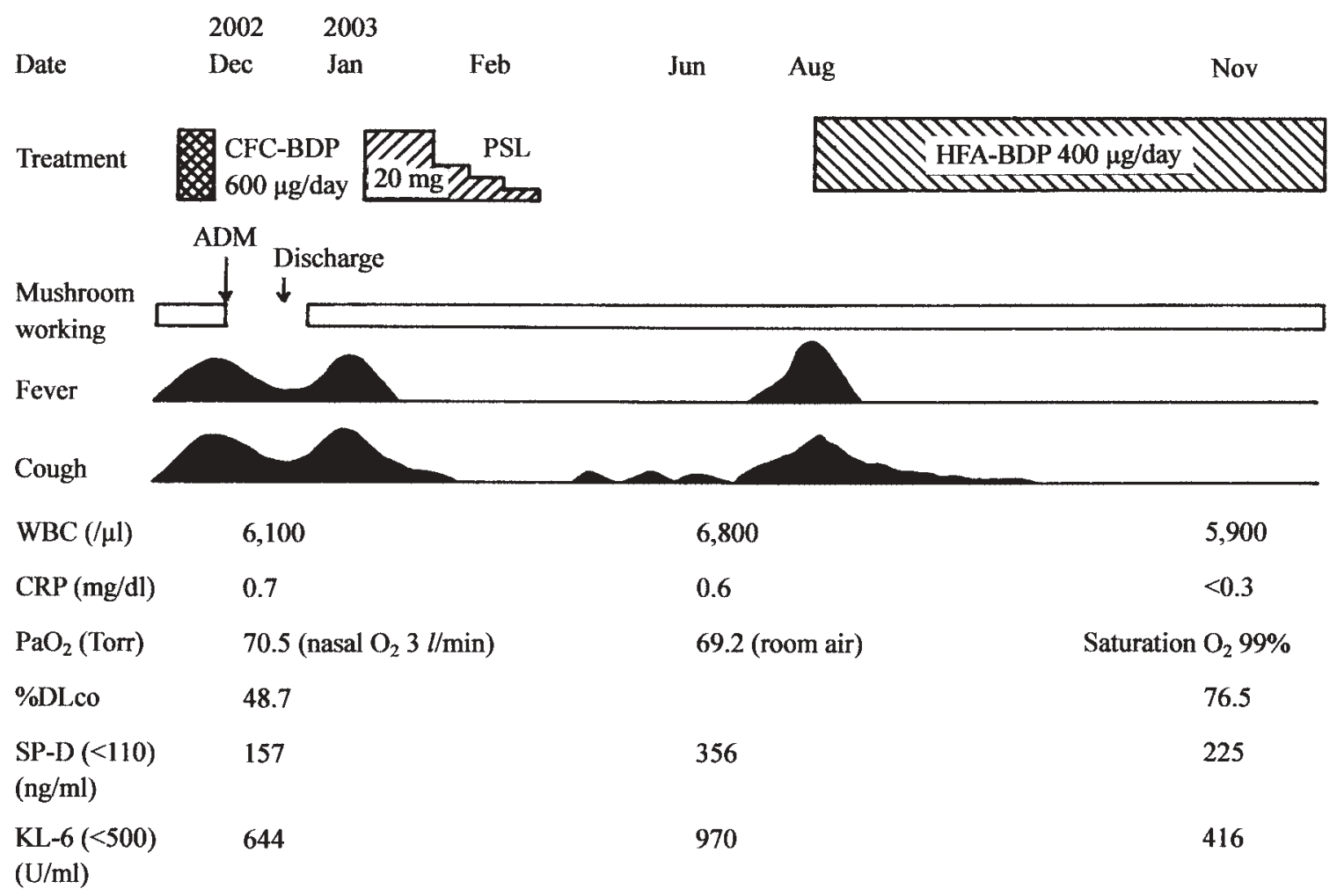

Figure 4. Clinical course.

slight cough, her percutaneous oxygen saturation recovered to $99 \%$, GGA and the centrilobular nodules on chest CT were markedly decreased (Fig. 2). Serum SP-D decreased to $225.6 \mathrm{ng} / \mathrm{ml}$ and serum KL-6 value returned to normal (416 $\mathrm{U} / \mathrm{ml})$. She continued to work in the same mushroom farm without exacerbation of her respiratory symptoms up to March 2004.

\section{Discussion}

Maitake is one of the common edible mushrooms in Japan, and is cultivated in large amounts in windowless rooms under high temperature and humidity. HP caused by inhaled mushroom spores has recently been increasingly reported, including Shiitake, Nameko, Shimeji, Bunashimeji, Eringi mushroom (1-5). However, there has been no report of HP induced by Maitake mushroom spores, and this patient is the first case. The spores of Maitake are 3 to $7 \mu \mathrm{m}$ in size, therefore they can reach the alveoli and potentially cause HP. The latent period was very short, 3 months, in this case, and previous reports for other spores described latent times varying from 2 months to 48 years (1-5). We previously reported that $71.4 \%$ of mushroom workers experienced an allergic chronic cough within 3 months after starting work in a Bunashimeji mushroom farm (8). We speculate that a high concentration of airborne mushroom spores may shorten the sensitization period in contemporary mushroom farms, and 3 months might be sufficient to be sensitized in such a situation.

In this case inhaled corticosteroid, chlorofluorocarbon (CFC)-BDP, was ineffective for her initial HP, but in her recurrent HP, inhaled corticosteroid, HFA-BDP, was effective. This reason for the difference in efficacy may be a difference in the disease severity. In the initial HP episode, hypoxemia was more severe than in the recurrence, and the mushroom spore concentration in the workplace during the initial disease would be more dense than that at recurrent HP. We speculated that the more severe HP would not be suppressed by inhaled corticosteroid alone, while for mild disease inhaled corticosteroid might be effective. But in this patient we could not elucidate the long-term efficacy of the drug on HP. There is a concern that incomplete suppression of pulmonary inflammation by inhaled croticosteroid without avoidance of inhaled causative antigens might lead to chronic HP. The standard therapy of HP is systemic steroid, consequently, controlled clinical trials of the long-term efficacy of inhaled corticosteroids to HP are required.

On the other hand, HFA-BDP was formulated in a MDI to deliver a smaller mean particle size of $1.1 \mu \mathrm{m}$ than the 3.5 $\mu \mathrm{m}$ for CFC-BDP product. HFA-BDP lung deposition was greater in the airways than was CFC-BDP (56\% vs 4-7\%) (9), suggesting that with its larger particle size CFC-BDP aerosol deposition in the peripheral airways of the lung might be minimal (10). HP mainly affects the alveolus, 
therefore extra-fine aerosol corticosteroid might effectively treat alveolitis due to HP. Serum SP-D and KL-6 are useful markers of HP activity $(2,11)$. Daily dose of $600 \mu \mathrm{g}$ of CFCBDP failed to suppress HP, however HP was inhibited and serum levels of SP-D and KL-6 decreased with a single treatment of $400 \mu \mathrm{g} /$ day of HFA-BDP in this patient. We presume that one explanation for the difference in therapeutic efficacy might be the difference in lung deposition rate for each inhaled steroid. Inhaled corticosteroids have been used in patients with pulmonary sarcoidosis, with several reports of some benefit from this therapy but not all studies have demonstrated clinical efficacy $(12,13)$. Controlled clinical trials of the efficacy of inhaled corticosteroids in HP are necessary.

\section{References}

1) Ishii M, Kikuchi A, Kudoh K, et al. Hypersensitivity pneumonitis induced by inhalation of mushroom (Pholiota Nemeko) spores. Intern Med 33: 683-685, 1994.

2) Tanaka H, Sugawara H, Saikai T, Tsunematsu K, Takahashi H, Abe $S$. Mushroom worker's lung caused by spores of Hypsizigus marmoreus (Bunashimeji); elevated serum surfactant protein D level. Chest 118: 1506-1509, 2000.

3) Tsushima K, Honda T, Kubo K. Hypersensitivity pneumonitis caused by Lyophyllum aggregatum in two sisters. Nippon Kokyuki Gakkai
Zasshi 38: 599-604, 2000.

4) Tsushima K, Fujimoto K, Yamazaki $Y$, et al. Hypersensitivity pneumonitis induced by spores of Lyophyllum aggregatum. Chest 120: 1085-1093, 2001.

5) Saikai T, Tanaka H, Fuji M, et al. Hypersensitivity pneumonitis induced by the spore of Pleurotus Eryngii (Eringi). Intern Med 41: 571573, 2002.

6) Carlsen KH, Leegaard J, Lund OD, Skjaervik H. Allergic alveolitis in a 12-year-old boy: treatment with budesonide nebulizing solution. Pediatr Pulmonol 12: 257-259, 1992.

7) du Marchie Sarvaas GJ, Merkus PJ, de Jongste JC. A family with extrinsic allergic alveolitis caused by wild city pigeons: A case report. Pediatrics 105: E62, 2000.

8) Tanaka H, Saikai T, Sugawara H, et al. Three-year follow-up study of allergy in workers in a mushroom factory. Respir Med 95: 943-948, 2001.

9) Leach CL, Davidson PJ, Boudreau RJ. Improved airway targeting with the CFC-free HFA-beclomethasoe metered-dose inhaler compared with CFC-beclomethasone. Eur Respir J 12: 1346-1353, 1998.

10) Conway JH, Holgate ST. Targeting therapy to inflamed airways in asthma. J Aerosol Med 7: 161-165, 1994.

11) Kohno N, Awaya Y, Oyama T, et al. KL-6, a mucin-like glycoprotein, in bronchoalveolar lavage fluid from patients with interstitial lung disease. Am Rev Respir Dis 148: 637-642, 1993.

12) Selroos O. Inhaled corticosteroids and pulmonary sarcoidosis. Sarcoidosis 5: 104-105, 1998.

13) Spiteri MA, Newman SP, Clarke SW, Poulter LW. Inhaled corticosteroids can modulate the immunopathogenesis of pulmonary sarcoidosis. Eur Respir J 2: 218-224, 1989. 